\title{
Binocular Diplopia
}

National Cancer Institute

\section{Source}

National Cancer Institute. Binocular Diplopia. NCI Thesaurus. Code C118718.

Perception of two images secondary to misalignment of the eyes. 